\title{
MONITORING SCRUB WEED CHANGE IN THE CANTERBURY REGION USING SATELLITE IMAGERY
}

\author{
J.D. SHEPHERD ${ }^{1}$, J.R. DYMOND ${ }^{1}$ and J.R.I. CUFF ${ }^{2}$ \\ ${ }^{1}$ Landcare Research, Private Bag 11052, Palmerston North, New Zealand \\ ${ }^{2}$ Environment Canterbury, P.O. Box 550, Timaru, New Zealand
}

Corresponding author: shepherdj@landcareresearch.co.nz

\begin{abstract}
The spatial change of woody vegetation in the Canterbury region was automatically mapped between 1990 and 2001 using Landsat satellite image mosaics. The intersection of valid data from these mosaics gave coverage of $84 \%$ of the Canterbury region. Changes in woody cover greater than 5 ha were identified. Of the 5 ha areas of woody change, only those that were likely to have been a scrub change were selected, using ancillary thematic data for current vegetation cover (e.g. afforestation and deforestation were excluded). This resulted in 2466 polygons of potential scrub change. These polygons were rapidly checked by visual assessment of the satellite imagery and assigned to exotic or indigenous scrub change categories. Between 1990 and 2001 the total scrub weed area in the Canterbury region increased by $3600 \pm 400$ ha, and indigenous scrub increased by $2300 \pm 400$ ha.
\end{abstract}

\section{INTRODUCTION}

The Environment Canterbury (ECAN) region includes 4.5 million ha or approximately $17 \%$ of the land area of New Zealand. Environment Canterbury currently has a Regional Pest Management Strategy (RPMS) that includes containment control for scrub weeds, specifically Ulex europeaus (gorse) and Cytisus scoparius (broom). Both gorse and broom have adverse effects on pastoral production, forming dense thickets that prevent stock from grazing and displacing pasture. Monitoring the effectiveness of scrub weed management is difficult as conventional weed mapping techniques are expensive, time consuming and often inefficient where the target weeds cover a wide geographic area. Satellite imagery is well suited to regional monitoring of land cover change due to the cost-effectiveness of automated classification techniques. Scrub weeds, due to their growth pattern, size and canopy characteristics, can be discriminated using remote sensing (Everitt et al. 1992; Gardiner et al. 1998). However, there are limitations; the target weeds must have distinct reflectance differences from background vegetation and detection can be limited by the density of infestation.

The current multi-spectral sensors have quite broad spectral bands and it can be difficult to resolve particular scrub weed species, as they can be too similar in structure and colour to be discriminated from native scrub, such as Leptospermum scoparium (manuka). Timing imagery to match scrub weed flowering can help with discrimination (Lass et al. 1996; Shepherd \& Lee 2002), although it is not often practical for large regions due to variation in flowering phenologies, cloud cover patterns, and data acquisition limitations for the many scenes required. For this historical study, it was not possible to try to discriminate between species by matching imagery to flowering patterns as, without priority requests at the time, only minimal satellite imagery is routinely acquired for a given location. Landsat satellite imagery was chosen for the ECAN coverage, because it was routinely acquired, has 6 spectral bands for classification, has a relatively extensive history (1975-) and it has reasonable resolution (30 m pixels), coverage per scene $(180 \mathrm{~km} \times 180 \mathrm{~km})$ and cost (\$US 600 per scene). 
In this paper, a semi-automated method for mapping scrub weed change is presented. The method uses automatic classification of satellite imagery for woody vegetation change. As land cover change is typically a small proportion of the actual land area, the woody vegetation change map forms an efficient basis for stratification of sampling effort to assign change categories. Manual interpretation of satellite imagery and other ancillary datasets such as ortho-photography is then used with the aid of purpose-built software to rapidly move and record information at each sample point.

\section{METHODS}

Mosaicking cloud-free coverage of the ECAN region required collection of a number of Landsat scenes. For the "recent" date (circa 2001), 10 Landsat 7 Enhanced Thematic mapper (ETM+) scenes were used, giving 99.4\% cloud-free coverage (Table 1). For the "past" date (circa 1990), 8 Landsat 4 Thematic Mapper (TM) scenes were used, giving $84.7 \%$ cloud-free coverage (Table 1).

TABLE 1: Landsat 7 ETM+ Satellite imagery used to form the 2001 mosaic and Landsat 4 TM Satellite imagery used to form the 1990 mosaic of the ECAN region.

\begin{tabular}{|c|c|c|c|c|c|}
\hline \multicolumn{3}{|c|}{2001 mosaic } & \multicolumn{3}{|c|}{1990 mosaic } \\
\hline Path/Row & Date (GMT) & Area (ha) & Path/Row & Date (GMT) & Area (ha) \\
\hline $73 / 89$ & 09-DEC-1999 & 372,368 & $73 / 89$ & 16-DEC-1990 & 364,164 \\
\hline $73 / 90$ & 09-DEC-1999 & 967,444 & $73 / 90$ & 16-DEC-1990 & 765,346 \\
\hline $74 / 90$ & 03-JAN-2001 & $1,385,043$ & $73 / 91$ & 16-DEC-1990 & 168,076 \\
\hline $74 / 90$ & 24-DEC-2002 & 998,849 & $75 / 91$ & 12-JAN-1990 & $1,228,655$ \\
\hline $76 / 91$ & 07-JAN-2003 & 20,322 & $75 / 90$ & 30-DEC-1990 & 725,064 \\
\hline $75 / 91$ & 01-FEB-2003 & 627,556 & $74 / 89$ & 23-DEC-1990 & 41,005 \\
\hline $75 / 90$ & 14-FEB-2002 & 132,499 & $74 / 90$ & 23-DEC-1990 & 554,072 \\
\hline $74 / 89$ & 20-FEB-2001 & 19,385 & $74 / 91$ & 23-DEC-1990 & 91,712 \\
\hline $74 / 90$ & 27-FEB-2000 & 97,808 & & & \\
\hline $74 / 90$ & 20-FEB-2002 & 3,308 & & & \\
\hline
\end{tabular}

The method of Dymond \& Shepherd (2004) was followed to ortho-rectify the Landsat satellite imagery and process it to standardised spectral reflectance. Standardised spectral reflectance is a property of the vegetation alone, as it has been corrected for the effects of sun position, slope and view direction. The imagery was then mosaicked with priority given to scenes with higher sun elevation, and spectrally-based rules were applied to automatically map woody and non-woody vegetation. This vegetation mapping method generally has an accuracy of better than $95 \%$ (Dymond \& Shepherd 2004). The intersection of the 1990 and 2001 woody vegetation maps gave an $84.4 \%$ coverage the ECAN region. Changes between the 1990 and 2001 coverages were extracted and a raster clump GIS analysis performed. This provided a list of change locations and sizes from the change map. The use of raster clumps improves the likelihood of finding correct change as it is expected that scrub weed management is at paddock rather than pixel scale. By limiting the search to 1 ha or greater, change clumps gave 36,043 locations, but classifying this number of locations was too large a task to complete in a reasonable time. Limiting the search to 5 ha or greater change clumps gave 5416 locations, a more reasonable list that still contains the majority of the mapped change area. However, some of these clumps contain non-target woody changes such as those associated with exotic forestry activities. By using an existing vegetation map, the New Zealand Land Cover 
Database (LCDB) (MFE undated), as recent date ancillary data the size of the task was further reduced. Choosing the non-woody to woody changes that were confirmed as being scrub at the second date and similarly choosing the woody to non-woody changes that were confirmed non-woody, reduced the list to 2466 locations (Table 2).

TABLE 2: Total number of automatically mapped woody and non-woody change clumps.

\begin{tabular}{lcr}
\hline Change Scenario & Size & \multicolumn{1}{c}{ Total } \\
\hline Woody to Non-Woody & $>1$ ha & 9,222 \\
Non-Woody to Woody & $>1$ ha & 26,821 \\
\cline { 2 - 2 } Woody to Non-Woody & $>5$ ha & 36,043 \\
Non-Woody to Woody & $>5$ ha & 1,346 \\
\cline { 2 - 2 } Woody to Non-Woody ( + Ancillary LCDB) & $>5$ ha & 4070 \\
Non-Woody to Woody ( + Ancillary LCDB) & $>5$ ha & 5,416 \\
\cline { 2 - 2 } & & 1,580 \\
\hline
\end{tabular}

A custom software tool was designed to "drive" an image viewer to the centroid location of each of the clumps by a single button press and to record attributes about the change transition by simple preset codes. Each 5 ha clump was then visually examined by an experienced mapper on a 4,5,3, band combination of the early and later satellite images displayed side by side. The colour of the clump, and the surrounding texture, pattern and context, were all used to decide on the change status. Where available, orthophotos were used to support the visual examination of the satellite imagery. Using this system it was possible to check and assign exotic or indigenous scrub categories to the 2466 clumps, in approximately 3 operator days (it was not always possible to confirm scrub type, in this case the clump remained unspecified). This method provided a cost-effective balance of the accuracy of manual interpretation with the focus provided by automated mapping.

\section{RESULTS AND DISCUSSION}

Table 3 shows that a large proportion of the area mapped as change was actually manually confirmed to be no change. This is to be expected even when individual date mapping accuracies are high, as any error tends to increase mapped change and true change is typically a small proportion of the monitored area. In this case confirmed scrub changes are less than $0.3 \%$ of the ECAN region. To calculate the change between exotic and indigenous scrub it was assumed that the unspecified scrub can be proportioned as in the other scrub change categories. The net increase in exotic scrub could then be estimated as $3600 \pm 400 \mathrm{ha}$, and the net increase in indigenous scrub as $2300 \pm 400 \mathrm{ha}$. In the ECAN region exotic scrub is dominated by gorse and broom, therefore this analysis indicates an increase in scrub weed cover between 1990 and 2001. 
TABLE 3: Total change in scrub area and type between 1990 and 2001.

\begin{tabular}{lc}
\hline Scrub Change & Area (ha) \\
\hline Exotic Scrub - No Change & 2,692 \\
Indigenous Scrub - No Change & 7,619 \\
Unspecified Scrub - No Change & 590 \\
Non-Scrub ${ }^{1}$ - No Change & 9,399 \\
\hline Exotic Scrub to Non-Scrub & 420 \\
Non-Scrub to Exotic Scrub & 4,307 \\
\hline Indigenous Scrub to Non-Scrub & 469 \\
Non-Scrub to Indigenous Scrub & 3,049 \\
\hline Unspecified Scrub to Non-Scrub & 674 \\
Non-Scrub to Unspecified Scrub & 192 \\
\hline
\end{tabular}

${ }^{1}$ Non-Scrub - either grassland or forest.

This method has potential as a cost-effective tool for regional scrub weed monitoring, such as that required for the ECAN RPMS. Although the RPMS was not in place throughout the period of this study, this work provides baseline information and techniques for the future. It is possible to extend this rapid analysis to a more comprehensive and statistically robust framework by using the change map as a basis for further stratified random sampling. This initial work can then be considered an exhaustive sampling of a stratum with high probability of change. The other strata would include change clumps less than 5 ha, woody to woody areas that exhibit a large change in reflectance, remaining woody to woody area, and non-woody to non-woody areas. Rather than exhaustively checking each of these strata, an appropriate number of random samples could be chosen depending on the detection probabilities and level of reporting accuracy required.

\section{REFERENCES}

Dymond JR, Shepherd JD 2004. The spatial distribution of indigenous forest and its composition in the Wellington region, New Zealand, from ETM+ satellite imagery. Remote Sensing of the Environment 90: 116-125.

Everitt JH, Escobar DE, Alaniz MA, Villarreal R, Davis MR 1992. Distinguishing brush and weeds on rangelands using video remote sensing. Weed Technology 6(4): 913-921.

Gardiner DB, Tupper GJ, Dudgeon GS 1998. A quantitative appraisal of woody shrub encroachment in Western New South Wales. Rangeland Journal 20(1): 26-40.

Lass LW, Carson HW, Callihan RH 1996. Detection of yellow starthistle (Centaurea solstitialis) and common St. Johnswort (Hypericum perforatum) with multispectral digital imagery. Weed Technology 10(3): 466-474.

MFE undated. Ministry for the environment - The New Zealand Land Cover Database. http://www.mfe.govt.nz/issues/land/land-cover-dbase/index.html (accessed 18 May 2007).

Shepherd JD, Lee WG 2002. Satellite mapping of gorse at regional scales. New Zealand Plant Protection 55: 95-98.

Shepherd JD, Dymond JR 2003. Correcting satellite imagery for the variance of reflectance and illumination with topography. International Journal of Remote Sensing 24(17): 3503-3514. 